\title{
Planejamento de carreira na visão de futuros engenheiros civis e jornalistas: um
}

\section{estudo de caso}

\author{
Career planning from the perspective of future civil engineers and journalists: a case study \\ Planificación de carrera desde la perspectiva de futuros ingenieros civiles y periodistas: un estudio
}

de caso

Recebido: 22/02/2021 | Revisado: 28/02/2021 | Aceito: 04/03/2021 | Publicado: 12/03/2021

Corina Alves Farinha

ORCID: https://orcid.org/0000-0003-4411-8409 Universidade do Estado de Minas Gerais, Brasil E-mail: corina.farinha@gmail.com Ayllana da Cunha Ferreira ORCID: https://orcid.org/0000-0002-4958-1251 Universidade do Estado de Minas Gerais, Brasil E-mail: ayllanaferreira@gmail.com

Gabriela Aparecida Bueno

ORCID: https://orcid.org/0000-0001-6941-8227 Universidade do Estado de Minas Gerais, Brasil E-mail: gabrielabueno.eng@gmail.com

Gabriela Fernandes Coelho

ORCID: https://orcid.org/0000-0002-6443-6052

Universidade do Estado de Minas Gerais, Brasil E-mail: gabrielacoelhoeng@gmail.com

\begin{abstract}
Resumo
Este trabalho objetivou entender planejamento de carreira na perspectiva discente por meio de uma pesquisa exploratória, descritiva, quali-quantitativa, com estudo de caso único. Foram analisados 72 planos de carreira, 53 elaborados pelos alunos de Engenharia Civil, e 19 do curso de Jornalismo. O entendimento de planejamento de carreira foi estabelecido em dois âmbitos: a aplicação da metodologia Plano de carreira, Oliveira (2009); e conceito de carreira de Dutra (2002). Plano de carreira envolve a visão de futuro profissional explicitado como um conjunto planejado de estágios interligados às necessidades individuais, empresariais e comunidade; e carreira envolve mudanças de aspirações, padrões de satisfação, autoconcepções e outras atitudes da pessoa voltadas para seu trabalho e a sua vida, considerando as mudanças da sociedade do mundo do trabalho, e foi apresentado por 5 discentes, Engenharia Civil, $10 \%$; e 7 do Jornalismo, 37\%. A elaboração do plano de carreira possibilitou autoconhecimento para 31 respondentes, 58,5\% do curso de engenharia civil e de 17 discentes, 89,5\% do curso de jornalismo. O estudo permitiu verificar que a gestão pessoal de carreira considerando aspectos de autoconhecimento, com base no desenvolvimento de um referencial próprio nas escolhas profissionais apontados como relevantes na literatura pesquisada, se encontra incipiente no grupo pesquisado.
\end{abstract}

Palavras-chave: Plano de carreira; Trabalho e educação; Engenharia e jornalismo.

\begin{abstract}
This work aimed to understand career planning in the student perspective through an exploratory, descriptive, qualiquantitative research, with a single case study.72 career plans were analyzed, 53 prepared by Civil Engineering students, and 19 from the Journalism course. The understanding of career planning was established in two areas: the application of the Career Plan methodology, Oliveira (2009); and Dutra's career concept (2002). Career plan involves the vision of professional future spelled out as a planned set of internships linked to individual, business and community needs; and career involves changes in aspirations, satisfaction standards, self-conceptions and other attitudes of the person focused on their work and their life, considering the changes in society in the world of work, and was presented by 5 students, Civil Engineering, 10\%; and 7 from Journalism, 37\%. The preparation of the career plan enabled self-knowledge for 31 respondents, $58.5 \%$ of the civil engineering course and 17 students, $89.5 \%$ of the journalism course. The study allowed to verify that the personal career management considering aspects of selfknowledge, based on the development of a specific reference in the professional choices pointed out as relevant in the researched literature, is incipient in the researched group.
\end{abstract}

Keywords: Career plan; Work and education; Engineering and journalism. 


\begin{abstract}
Resumen
Este trabajo tuvo como objetivo comprender la planificación de la carrera en la perspectiva del estudiante a través de una investigación exploratoria, descriptiva, cuali-cuantitativa, con un solo estudio de caso. Se analizaron 72 planes de carrera, 53 elaborados por estudiantes de Ingeniería Civil y 19 del curso de Periodismo. La comprensión de la planificación de la carrera se estableció en dos areas: la aplicación de la metodología del Plan de Carrera, Oliveira (2009); y el concepto de carrera de Dutra (2002). El plan de carrera implica la visión de futuro profesional explicada como un conjunto planificado de pasantías vinculadas a las necesidades individuales, empresariales y comunitarias; y carrera implica cambios en las aspiraciones, estándares de satisfacción, autoconcepciones y otras actitudes de la persona enfocada en su trabajo y vida, considerando los cambios de la sociedad en el mundo laboral, y fue presentada por 5 estudiantes, Ingeniería Civil, 10\%; y 7 de Periodismo, 37\%. La elaboración del plan de carrera permitió el autoconocimiento de 31 encuestados, el 58,5\% de la carrera de ingeniería civil y 17 estudiantes, el 89,5\% de la carrera de periodismo. El estudio permitió constatar que la gestión de la carrera personal considerando aspectos del autoconocimiento, a partir del desarrollo de un referente específico en las elecciones profesionales señaladas como relevantes en la literatura investigada, es incipiente en el grupo investigado.
\end{abstract}

Palabras clave: Plan de carrera; Trabajo y Educación; Ingeniería y periodismo.

\title{
1. Introdução
}

Este trabalho surgiu da problematização do contexto sócio, econômico, político e cultural do país na disciplina Princípios de Economia lecionada nos cursos de Engenharia Civil e Jornalismo em uma Instituição de Ensino Superior Estadual- IES na cidade Divinópolis, MG.

A disciplina objetiva estudo integrado e crítico do pensamento econômico, principais características, teóricos em destaque, e possibilidades de aplicação. Nesse contexto, a sala de aula torna-se ambiente propício às discussões sobre futuro profissional dos discentes visto que a inserção do aluno, futuro profissional, no mundo do trabalho e a garantia de um emprego não são assegurados após a conclusão do curso. As discussões levaram à seguinte indagação: Qual é o entendimento de planejamento de carreira na visão discente? O objetivo do estudo foi entender planejamento de carreira na perspectiva discente. Os dados foram analisados sob dois âmbitos teóricos: Oliveira (2009) metodologia de Plano de carreira; e, Dutra (2002) conceito de carreira baseado em London e Stumph (1982).

Estudos desenvolvidos por Chanlat (1995) indicam que a carreira, as profissões e a estrutura dos empregos fazem parte da natureza da sociedade. Dessa forma, a cultura a estrutura social, política e econômica modificam o entendimento, tipos e modelos de carreira. A ideia de carreira surge no decorrer do século XX baseada em reconhecimento e mobilidade social. A industrialização tornara possível fazer carreira - entendida como um ofício, uma profissão que apresenta etapas, uma progressão - no interior das organizações. Porém, desde os anos 1970 e o início dos anos 2000 as mudanças trazidas pela globalização da economia, das crises econômicas, do petróleo, competitividade mundial e os novos modelos organizacionais de produção provocaram profundas mudanças culturais e sociais afetando o mundo do trabalho. Se, por um lado, as empresas passaram a dar maior relevância à profissionalização da gestão organizacional e de carreira focando na contribuição das pessoas para o desempenho das organizações, por outro, o assumir a responsabilidade pela construção da carreira passa a ser do indivíduo. O desenvolvimento de uma carreira ocorre na perspectiva individual e organizacional (Chanlat, 1995; Dutra, 2002; Veloso, 2012). O indivíduo, como construtor de uma trajetória profissional, avalia saberes, competências, experiências profissionais em consonância com os objetivos pessoais. Nas organizações, a carreira envolve políticas, procedimentos e decisões ligadas à gestão de pessoas e busca alinhar os objetivos empresariais e em certa medida, dos colaboradores recrutados a permanecer na empresa (Dutra, 2009, 2010; Veloso, 2012).

A relevância de oferecer às pessoas uma reflexão sobre objetivos, interesses, oportunidades e desafios para ingressar ou permanecer no mundo do trabalho nos estudos em que abordam a carreira como responsabilidade individual é partilhada por Dutra (2002, 2009, 2010), Oliveira (2009), Veloso (2012) e Martins (2010). Para esses autores as pessoas devem desenvolver uma visualização de novas possibilidades de ação, considerando a estrutura de uma organização, o autoemprego e a própria preparação futura. Já a discussão do conceito de carreira na perspectiva do indivíduo é posta em Hall (2002) em 
Veloso (2012) e refere-se à "sequência individualmente percebida de atitudes e comportamentos associada com experiências relacionadas ao trabalho e atividades durante a vida de uma pessoa." Dutra (2009) evidencia que as pessoas ao pensar em carreira devem prospectar o seu futuro, tomando como referência o próprio potencial, analisando novos espaços de trabalho, construindo projetos pessoais.

Martins (2010) considera a necessidade de autoconhecimento para que a pessoa desenvolva um referencial próprio nas escolhas profissionais. Para tanto, se faz necessário planejar a carreira, elaborar um projeto profissional, um plano de ação. Oliveira (2009) observando a dificuldade das pessoas em estabelecer seus caminhos profissionais, como o direcionamento de uma atividade profissional específica, a escolha de curso universitário ou técnico, orientação num processo seletivo perante vagas de emprego, redirecionamento profissional perante ameaças e oportunidades no mundo do trabalho elaborou uma metodologia de elaboração de plano de carreira.

Por outro lado, Dutra (2010) constatou nas intervenções realizadas em empresas e trabalhos com estudantes de cursos superiores, a tendência das pessoas em guiar suas carreiras por fatores externos como remuneração, status, prestígio e não em suas preferências pessoais apresentando resistência ao planejamento individual de carreira. $O$ autor salienta que um planejamento de carreira contribui para a autoavaliação, estabelecimento de objetivos e a identificação de oportunidades de carreira. Oliveira (2009) aponta a dificuldade das pessoas em pensar e trabalhar o futuro profissional e de estruturar formalmente um plano de carreira para inserção profissional.

O conceito de carreira associado ao sinônimo de trabalho, ocupação, profissão e vocação está atrelada a uma concepção tradicional de carreira surgida no transcorrer do século XX e permaneceu até meados dos anos 1970. Basicamente direcionada ao mundo masculino e identificada pela progressão linear vertical por meio de posições carregadas de responsabilidades crescentes, status e recompensas dadas pela organização. Estas forneciam treinamento e oportunidades dirigindo plano de carreira formalizado e a tendência dos trabalhadores, demonstrando lealdade e trabalho duro, a passar toda a trajetória de labor com o mesmo empregador. Os estudos de London e Stumph (1982), em Dutra (2002), apontam ao entendimento de carreira como a ocorrência de transições ligadas a necessidades individuais e imposições da organização e da sociedade. Trata-se da sequência de posições ocupadas e de trabalhos realizados durante a vida profissional de uma pessoa. Nessa perspectiva, fatores imprevisíveis e dinâmicos cuja construção envolve pressões originadas no próprio indivíduo, circunstâncias impostas pela sociedade bem como, pelas organizações integram a carreira. Para Arthur, Hall e Lawrence (1989) a carreira envolve a sequência de experiências profissionais, sendo que o trabalho influencia a maneira como os indivíduos enxergam e interagem com outras pessoas, organizações e sociedade. Para Dutra (2010) a carreira contempla uma perspectiva variável da interação entre o indivíduo e a sociedade e as organizações, inseridas na sociedade são responsáveis, por oferecer suporte e condições aos trabalhadores e estes a gestão do desenvolvimento pessoal e profissional, ou seja, de sua carreira.

Os estudos em torno de carreira, de forma estruturada num plano de ação, num Plano de Carreira, e na perspectiva da gestão da carreira realizada pelo indivíduo, iniciaram-se na década de 1990. Para Dutra (2010) os estudos sobre a carreira são importantes em um ambiente de transformação, pois auxiliam trabalhadores e organizações a compreender em maior profundidade a realidade em que vivem. A recomendação visa minimizar equívocos que podem significar sofrimento e perdas, riscos e prejuízos para indivíduos e organizações. A reflexão sobre a carreira deve ir além da identificação de oportunidades profissionais, das estruturas existentes nas empresas ou no mercado de trabalho, da sucessão de cargos ou posições no organograma.

Dutra (2002) aponta a tendência das pessoas a entender a trilha profissional como algo dado havendo falta de estímulo para elaboração de um plano de carreira levando-as a não realizar autoavaliação quanto a interesses e potencial para vários espaços organizacionais. Porém, em momentos de crise e escassez de empregos as pessoas buscam conselhos, métodos e 
instrumentos que as ajudem no processo de inserção no mundo do trabalho. O plano de carreira contribui para análise e construção de um perfil profissional e confrontando as demandas organizacionais bem como possibilidades de ações empreendedoras consigo próprias. Um plano de carreira formalizado proporciona posicionamento consciente quanto à trajetória profissional.

Oliveira (2009) apresenta uma metodologia para elaboração e aplicação de um plano estruturado de carreira, no qual, contempla seis fases analíticas: mercado atual e futuro; vocação e capacitação profissional; estabelecimento de vantagem competitiva; objetivos e estratégias; código de ética profissional e evolução profissional. Estas fases, divididas em subfases, visam aprofundar os temas conforme o Quadro 1.

Quadro 1. Plano de carreira.

\begin{tabular}{|c|c|}
\hline Etapas & Fase 1 - Análise do mercado atual e futuro \\
\hline 1.1. Estabelecimento da visão & $\begin{array}{l}\text { Identificação do que o indivíduo quer ser, dentro de um período de tempo } \\
\text { mais longo e abordagem mais ampla. }\end{array}$ \\
\hline $\begin{array}{l}\text { 1.2. Estabelecimento } \\
\text { dos valores pessoais }\end{array}$ & $\begin{array}{l}\text { Conjunto de princípios, crenças e questões éticas que sustentam todas as suas } \\
\text { principais decisões. }\end{array}$ \\
\hline 1.3. Identificação de oportunidades e ameaças & $\begin{array}{l}\text { Situações no mercado de trabalho que favorecem ou prejudicam o futuro se } \\
\text { conhecidas e trabalhadas. }\end{array}$ \\
\hline 1.4. Debate de cenários & Situações, critérios e medidas para a preparação do futuro. \\
\hline Etapas & Fase 2 - Análise da vocação e capacitação profissional \\
\hline 2.1. Vocação profissional & Aptidão pessoal para uma atividade específica \\
\hline 2.2. Capacitação profissional & Habilidade de identificar, adquirir, aplicar conhecimentos na área de atuação. \\
\hline Pontos fortes & Características positivas, relevantes. \\
\hline Pontos fracos & Características prejudiciais, inadequadas. \\
\hline $\begin{array}{l}\text { 2.3. Estabelecimento da missão e focos de } \\
\text { atuação }\end{array}$ & $\begin{array}{l}\text { Razão de ser, o que impulsiona uma pessoa a fazer alguma coisa; espaço de } \\
\text { atuação. }\end{array}$ \\
\hline 2.4. Estabelecimento da postura estratégica & $\begin{array}{l}\text { Cruzamentos entre ameaças e oportunidades do mercado e pontos fortes e } \\
\text { fracos do indivíduo. }\end{array}$ \\
\hline Etapas & Fase 3 - Estabelecimento da diferenciação competitiva \\
\hline 3.1. Análise dos concorrentes & Identificação e conhecimento dos concorrentes no mercado de trabalho \\
\hline 3.2. Diferenciação competitiva & Identificação de característica pessoal relevante \\
\hline Etapas & Fase 4 - Estabelecimento dos objetivos e metas \\
\hline 4.1. Objetivos e metas & $\begin{array}{l}\text { Etapas para o alcance de resultados quantificáveis com prazos para } \\
\text { realização. }\end{array}$ \\
\hline 4.2. Estratégias e projetos & Maneiras, alternativas para alcançar os objetivos. \\
\hline Etapas & Fase 5 - Estabelecer código de ética profissional \\
\hline 5.1. Políticas & Critérios orientadores do comportamento \\
\hline 5.2. Código de ética profissional & Normas de conduta profissional \\
\hline
\end{tabular}




\begin{tabular}{|c|c|}
\hline Etapas & Fase 6 - Análise da evolução profissional \\
\hline 6.1. Evolução profissional & Realização do plano de carreira, desempenho. \\
\hline 6.2. Estratégias, aprimoramento & Avaliação dos resultados, monitoramento. \\
\hline 6.3. Qualidade total do plano de carreira & $\begin{array}{l}\text { Atendimento às expectativas entre o plano de carreira individual e gestão de } \\
\text { carreira organizacional. }\end{array}$ \\
\hline Conhecimentos & Análise dos conhecimentos, habilidades e atitudes \\
\hline $\begin{array}{l}\text { 1. Elevado nível de conhecimento atividade } \\
\text { profissional escolhida } \\
\text { 2. Administração } \\
\text { 3. Generalista ou especialista } \\
\text { 4. Cultura geral, interesses e experiências } \\
\text { diversificadas. } \\
\text { 5. Inovação } \\
\text { 6. Administração do tempo } \\
\text { 7. Ser ético } \\
\text { 8. Resolução de problemas }\end{array}$ & $\begin{array}{l}\text { Conhecimento é capacidade de entender o conceito e a estruturação de um } \\
\text { assunto ou atividade e a respectiva aplicação em situação real de trabalho. }\end{array}$ \\
\hline $\begin{array}{l}\text { Habilidades: saber fazer } \\
\text { 1. Atitude interativa } \\
\text { 2. Relacionamento interpessoal } \\
\text { 3. Capacidade de lidar com erros } \\
\text { 4. Autoavaliação } \\
\text { 5. Agente de mudança } \\
\text { 6. Intuição } \\
\text { 7. Trabalho em equipe } \\
\text { 8. Resolução de conflitos } \\
\text { 9. Aberto a novas tarefas } \\
\text { 10. Adaptação às mudanças } \\
\text { 11. Facilidade de comunicação } \\
\text { 12. Postura profissional }\end{array}$ & Habilidade: demonstração saber-fazer algo; experiência. \\
\hline $\begin{array}{l}\text { Atitudes } \\
\text { 1. Autoconfiança } \\
\text { 2. Capacidade de aprendizado contínuo } \\
\text { 3. Flexibilidade profissional } \\
\text { 4. Autodesenvolvimento } \\
\text { 5. Mobilidade } \\
\text { 6. Interação: Carreira e qualidade de vida }\end{array}$ & Atitude é a explicitação do comportamento \\
\hline Etapas & Fase 2.4 - Fatores condicionantes do plano de carreira \\
\hline $\begin{array}{l}\text { 1. Relacionamentos } \\
\text { 2. Mudanças } \\
\text { 3. Estrutura de Poder } \\
\text { 4. Riscos e frustrações }\end{array}$ & $\begin{array}{l}\text { Fatores condicionantes são fatores externos que podem interferir } \\
\text { positivamente ou não a vida profissional. }\end{array}$ \\
\hline
\end{tabular}

Fonte: Adaptado de Oliveira (2009).

De acordo com Oliveira (2009) os usuários do plano de carreira se dividem entre primários e secundários. De um lado, os usuários primários são caracterizados como profissionais responsáveis pela elaboração e aplicação do plano, do outro lado, os secundários são as empresas onde tais profissionais trabalham. O plano de carreira apresenta particularidades, uma vez que não é padronizado para todo e qualquer indivíduo. Dentre as suas finalidades destacam-se: facilitar a interligação entre conhecimentos diversos; dar foco de direcionamento profissional para as pessoas; facilitar se necessário, a alteração do rumo profissional; dar mais segurança além de propiciar amplo debate da vida profissional das pessoas. 
Nesse contexto, a carreira como responsabilidade individual exige um planejamento, um plano de ação escrito que possibilitará elencar valores, interesses e habilidades. Valores de trabalho envolve conhecimento do tipo de ocupação, ramos de atividade e habilidades necessárias que impactam no estilo de vida. Os interesses relacionados a atividades realizadas ou a realizar em razão de interesse pessoal, envolvimento genuíno com a tarefa. A compatibilidade de valores vivenciados pelo indivíduo em sua ocupação está relacionada ao grau de bem-estar e autoestima. Assim, ter/elaborar um plano pessoal de carreira contribui para a tomada de decisões considerando o que é importante na vida e no trabalho num complexo processo de escolhas pessoais em ação mútua com o ambiente profissional.

Assim, o estudo sobre carreira apresentado neste trabalho surgiu da problematização do contexto sócio, econômico, político e cultural do país na disciplina Princípios de Economia lecionada nos cursos de Engenharia Civil e Jornalismo em uma Instituição de Ensino Superior Estadual - IES na cidade Divinópolis, MG. A disciplina objetiva estudo integrado e crítico do pensamento econômico, principais características, teóricos em destaque, e possibilidades de aplicação. Nesse contexto, a sala de aula tornou-se ambiente propício às discussões sobre futuro profissional dos discentes visto que a inserção do aluno, futuro profissional, no mundo do trabalho e a garantia de um emprego não são assegurados após a conclusão do curso. As discussões levaram à seguinte indagação, sendo o objetivo principal: Qual é o entendimento de planejamento de carreira na visão discente? Supôs-se que o grupo pesquisado tenderia definir objetivos e metas profissionais avaliando o seu perfil estudantil/profissional e as oportunidades do mercado no presente, desconsiderando planejamento de carreira como responsabilidade individual. O objetivo do estudo é entender o planejamento de carreira na perspectiva discente.

\section{Metodologia}

A opção metodológica deste trabalho circunscreve-se ao entendimento de planejamento de carreira na visão discente em dois âmbitos: plano de carreira e conceito de carreira. Trata-se de um estudo exploratório e descritivo. Para Gil (2008) uma pesquisa exploratória proporciona uma visão geral acerca de determinado fato, esclarecendo conceitos e ideias; e a descritiva aponta características de um fenômeno, levantando opiniões, atitudes e crenças de uma população e utilização de técnica padronizada de coleta dados. Assim, a pesquisa envolve dados qualitativos e quantitativos. Para Minayo (2002) estudos qualitativos trabalham com o universo dos significados, motivos, das ações e relações humanas, desvelando um lado não perceptível e não captável em medidas estatísticas. Uma pesquisa quantitativa, de acordo com Richardson (2017), é caracterizada pelo emprego da quantificação, tanto na coleta dos dados quanto no tratamento recorrendo à estatística permitindo generalização dos resultados.

Trata-se de um estudo de caso, pois o objeto principal se reporta ao entendimento de planejamento de carreira na perspectiva discente, estudantes do curso de graduação em Engenharia Civil e de Jornalismo de uma Instituição de Ensino Superior na cidade de Divinópolis - MG. Um estudo de caso para Yin (2005, p. 32) é "uma investigação empírica que investiga um fenômeno contemporâneo dentro de seu contexto da vida real, especialmente quando os limites entre o fenômeno e o contexto não estão claramente definidos". A unidade de análise deve estar relacionada à maneira como as questões iniciais da pesquisa foram definidas. No caso em pauta, a unidade de análise é uma Instituição de Ensino Superior Unidade Divinópolis selecionada intencionalmente por facilidade de acesso às informações necessárias para a eficiência deste trabalho. Os participantes constam dos discentes do $9^{\circ}$ período do curso de engenharia civil e do $3^{\circ}$ período de jornalismo matriculados na disciplina Princípios de Economia. Afirma Yin (2005) que os estudos de caso reúnem numerosas e detalhadas informações acerca de uma situação, podendo utilizar-se de várias técnicas de coleta de dados. Para consecução desta pesquisa, os dados foram coletados por meio de preenchimento de formulário plano de carreira, detalhado no item Plano de Carreira e de um pequeno texto no qual o participante descreveu como se sentiu ao preencher o plano. O objetivo da reflexão foi relacionar as 
percepções dos discentes com os dados sobre visão de futuro e conceito de carreira contribuindo para elucidar o entendimento do tema.

A Unidade de Análise, Instituição de Ensino Superior, selecionada intencionalmente dada facilidade de acesso às informações necessárias. Esta pesquisa, tutelada pela instituição, foi aprovada com projeto submetido ao Edital PROINPE 12019. A Instituição de Ensino Superior ${ }^{1}$ foi criada em 1989, por disposição contida na Constituição do Estado. É uma universidade multicampi presente em 16 municípios do Estado de Minas Gerais e 20 unidades, oferecendo 118 cursos de graduação (presencial e Ensino a Distância), pós-graduação 27 Lato Sensu, 8 mestrados e 2 doutorados. A Unidade Divinópolis oferece 17 cursos de graduação presencial, 6 cursos de pós-graduação presencial e um na modalidade à distância.

Os dados qualitativos foram submetidos à análise de conteúdo de Bardin (2011) gerando categorias relacionadas à base teórica de Oliveira (2009) plano de carreira: conceito e item 1.1 estabelecimento da visão, bem como, Dutra (2009) e London e Stumph (1982) conceito de carreira. Esses conceitos estão expostos resumidamente no Quadro 2.

Quadro 2. Base conceitual para categorização.

\begin{tabular}{|l|l|l|}
\hline \multicolumn{2}{|c|}{ Oliveira (2009) } & Dutra (2009) \\
\hline Estabelecimento da visão & Plano de Carreira & Conceito de Carreira \\
\hline $\begin{array}{l}\text { Identificação clara e objetiva } \\
\text { do que o indivíduo quer ser dentro de } \\
\text { um período mais longo. }\end{array}$ & $\begin{array}{l}\text { Explicitação formal de um conjunto } \\
\text { planificado, estruturado, sustentado e } \\
\text { sequencial de estágios que consolidam a } \\
\text { realidade evolutiva de cada indivíduo, } \\
\text { de forma interativa com as necessidades } \\
\text { da empresa e das comunidades onde } \\
\text { elas atual. Traduz o que o indivíduo } \\
\text { quer ser. }\end{array}$ & $\begin{array}{l}\text { Transições ligadas a necessidades } \\
\text { individuais e imposições da organização } \\
\text { e da sociedade. Sequência de posições e } \\
\text { profissional de uma pessoa, abrange } \\
\text { uma série de estágios e transições que } \\
\text { variam conforme pressões originadas do } \\
\text { próprio indivíduo e no ambiente. }\end{array}$ \\
\hline
\end{tabular}

Fonte: Autores. (2021).

Após o estudo da teoria e das categorias de ambos os autores, partiu-se para os critérios de análise, divididos entre a visão de futuro, o conceito de plano e o conceito de carreira, segundo o Quadro 3.

Quadro 3. Critérios para categorias de análise.

\begin{tabular}{|l|l|}
\hline \multicolumn{2}{|c|}{ Critérios para categorização } \\
\hline $\begin{array}{l}\text { Análise do Item 1.1 } \\
\text { Estabelecimento da visão }\end{array}$ & Critério \\
\hline $\begin{array}{l}\text { Visão de futuro } \\
\text { Conceito de plano } \\
\text { Conceito de carreira }\end{array}$ & $\begin{array}{l}\text { Indicar objetivamente o que quer ser e prazo para realização. } \\
\text { Apresentar: estágios evolutivos para realização do plano e evolução pessoal } \\
\text { interativos com a organização e sociedade. }\end{array}$ \\
\hline
\end{tabular}

Fonte: Autores. (2021).

Com os critérios de diagnóstico observados, estes foram correlacionados com as respostas dos alunos para a categorização final, mais aprofundada e específica, como exposto no Quadro 4.

\footnotetext{
${ }^{1}$ https://www.uemg.br/T
} 
Quadro 4. Categorias de análise.

\begin{tabular}{|l|l|}
\hline Categorias analíticas & Descrição da categoria \\
\hline Responsabilidade individual & $\begin{array}{l}\text { Visão objetiva. Há sequência de estágios que consolidam a evolução profissional e } \\
\text { projeto pessoal. Considera necessidades da sociedade e a contribuição da } \\
\text { engenharia/jornalismo. }\end{array}$ \\
\hline Tradicional - Área de atuação & $\begin{array}{l}\text { Visão focada no ramo, área de atuação ou cargo a ocupar. Foco na profissionalização e } \\
\text { reconhecimento. }\end{array}$ \\
\hline Tradicional - As coisas acontecem & $\begin{array}{l}\text { Visão vaga. Almeja satisfação pessoal, reconhecimento profissional, realizar sonhos } \\
\text { sem apresentar plano concreto. Reflete aspirações pessoais e profissionais, lamenta a } \\
\text { concorrência, mercado de trabalho fraco, mas espera melhorar. }\end{array}$ \\
\hline $\begin{array}{l}\text { Fatores externos - Sucesso de } \\
\text { qualquer maneira }\end{array}$ & $\begin{array}{l}\text { Visão breve e superficial, não há menção de área específica de atuação. Almeja } \\
\text { prestígio profissional, estabilidade financeira, sucesso. Foco em si mesmo explicitando } \\
\text { sucesso. }\end{array}$ \\
\hline $\begin{array}{l}\text { Fatores externos - Mercado de } \\
\text { trabalho }\end{array}$ & $\begin{array}{l}\text { Visão pessimista do mercado de trabalho. Lamenta concorrência, espera melhorar, falta } \\
\text { de perspectiva. }\end{array}$ \\
\hline
\end{tabular}

Fonte: Autores. (2021).

Assim sendo, conforme as respostas dos alunos e os conceitos dos autores mencionados, as categorias foram divididas em "responsabilidade individual”, "tradicional” (“área de atuação" ou "as coisas acontecem”), “fatores externos” (“sucesso de qualquer maneira" ou "mercado de trabalho"), conforme as descrições apontadas.

\section{Resultados e Discussão}

Para melhor entendimento da pesquisa, a Tabela 1 apresenta a distribuição dos 72 participantes separados por curso.

Tabela 1. Participantes da pesquisa.

\begin{tabular}{c|c|c}
\hline Curso & Quantidade & $(\%)$ \\
\hline Eng. Civil & 53 & 74 \\
\hline Jornalismo & 19 & 26 \\
\hline Total & $\mathbf{7 2}$ & $\mathbf{1 0 0}$ \\
\hline
\end{tabular}

Fonte: Autores. (2021).

Com a quantidade de alunos por curso e as categorias de cada um, foi feita a distribuição dos dados por categoria e curso resultante da análise e interpretação do Plano de carreira, item 1.1. Estabelecimento da visão modelo de Oliveira (2009) confrontado com o conceito de carreira de Dutra (2002), permitiu estabelecer o entendimento de conceito de plano e de carreira na visão discente, exibidos no Gráfico 1. 
Gráfico 1. Planejamento de carreira na visão discente por curso.

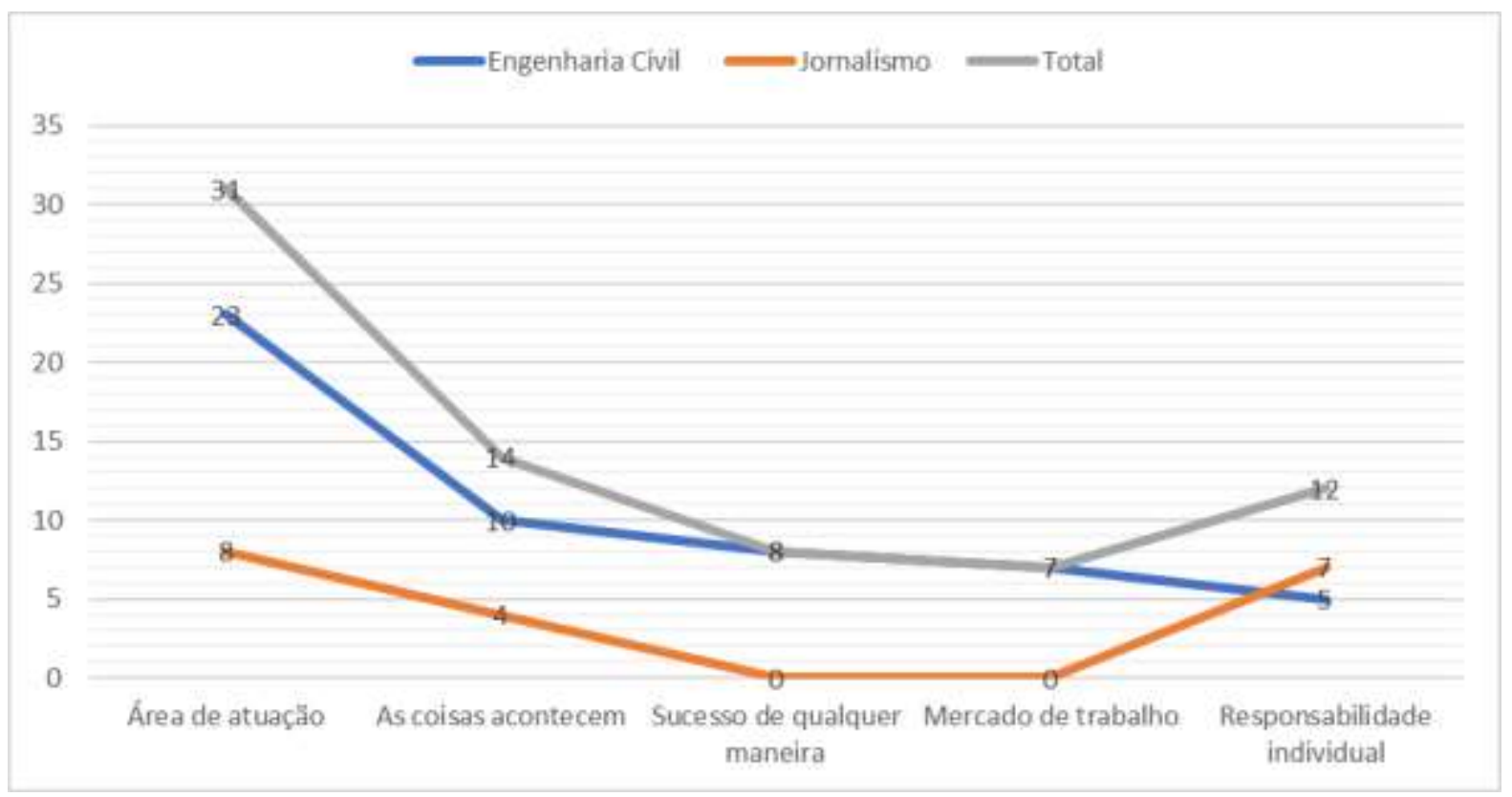

Fonte: Autores. (2021).

Plano de carreira de acordo com Oliveira (2009) é a explicitação formal de um conjunto planejado, estruturado, sustentado e sequencial de estágios interligados que consolidam a realidade evolutiva de cada indivíduo, de forma interativa às necessidades individuais, empresariais e comunidade identificada. $\mathrm{O}$ estabelecimento da visão comporta aquilo que o discente quer ser num determinado prazo. O conceito de carreira de Dutra (2002) reforça a concepção de plano de carreira de Oliveira (2009) abordando a ocorrência de transições profissionais ligadas a necessidades individuais e imposição organizacional e da sociedade.

A categoria "Tradicional - Área de atuação" traz um entendimento de plano e de carreira restrito a uma área de atuação profissional, uma vez que a visão de futuro de 23 discentes, $43 \%$ dos respondentes de Engenharia civil, e 8 de Jornalismo, $42 \%$, explicitaram o desejo de futuramente ocupar áreas e cargos específicos unicamente. Tal entendimento revela visão tradicional de carreira, entendida como ofício, uma profissão e crescimento numa organização (Chanlat, 1995).

Já a categoria "Tradicional - As coisas acontecem", corresponde a 10 respondentes, 19\% dos discentes de Engenharia Civil e 4 de Jornalismo, $21 \%$ dos participantes, refere-se ao entendimento que o futuro profissional é algo dado, que acontece de alguma forma e a responsabilidade pela inserção profissional é das organizações ao ofertarem vagas.

Por sua vez, a categoria "Fatores externos - Sucesso de qualquer maneira" refere-se a 8 discentes, $15 \%$ de Engenharia Civil e relacionam a carreira a fatores externos, como remuneração e prestígio, como aponta Dutra (2002).

A categoria "Fatores externos - mercado de trabalho", apontado por 7 discentes, 13\% do curso de Engenharia Civil, refere-se ao entendimento da carreira dependente das condições do mundo do trabalho percebendo-se certa resistência para planejar a carreira característica encontrada por Dutra (2002) no trabalho com universitários.

Por fim, a categoria "Responsabilidade individual" corresponde a 5 respondentes, $10 \%$ de engenharia Civil, e 7 discentes, 37\% de Jornalismo, neste caso os respondentes ao apresentarem visão objetiva, sequência de estágios e evolução profissional num projeto pessoal de vida consideraram as necessidades próprias da sociedade e contribuições da área especifica de saber, demonstrando que o indivíduo é construtor de uma trajetória profissional, avaliando saberes, competências, experiências profissionais e consonância com os objetivos pessoais. 
O Gráfico 2 refere-se aos sentimentos dos respondentes ao preencher o plano de carreira, representados no eixo X, e a quantidade de pessoas, colocada no eixo Y.

Gráfico 2. Percepção discente sobre a atividade plano de carreira.

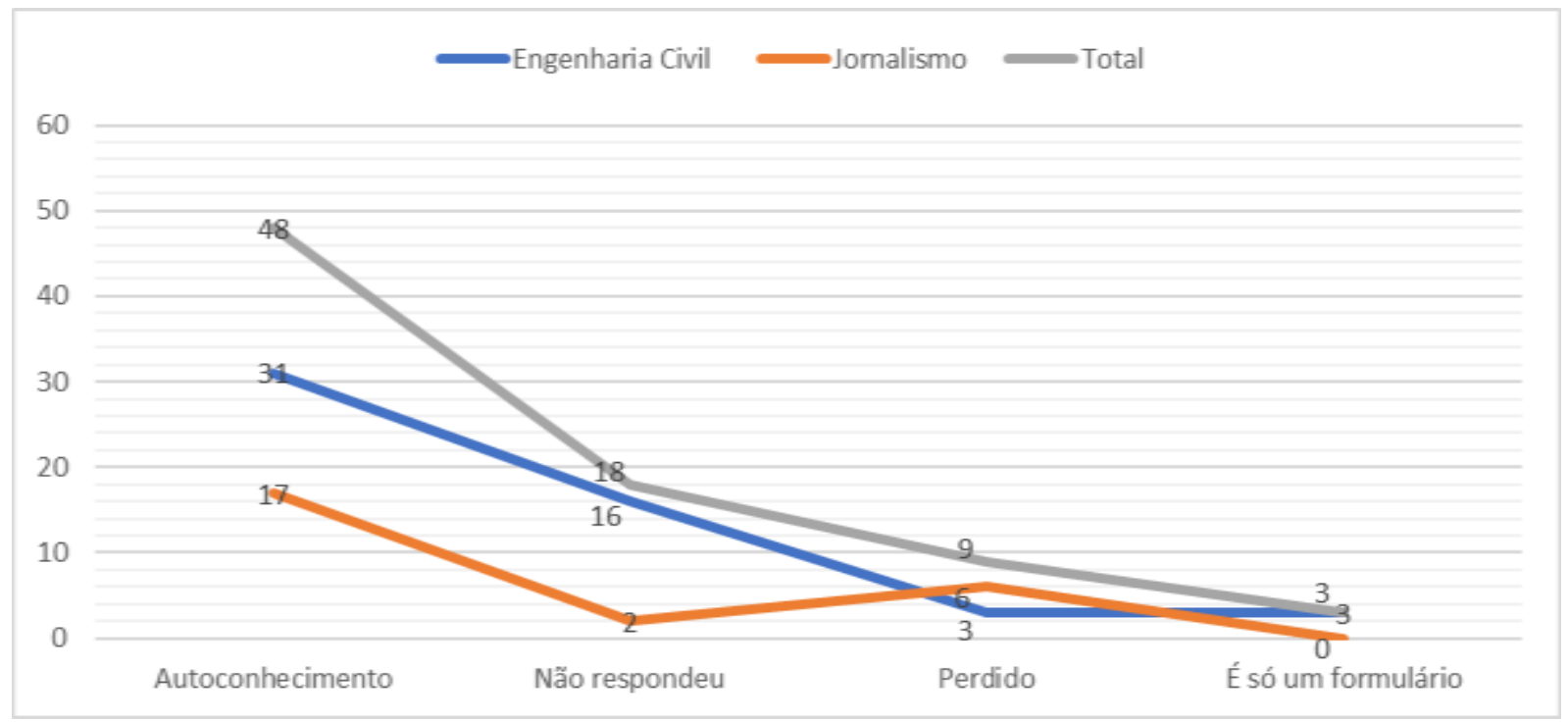

Fonte: Autores. (2021).

De acordo com o relato de 31 discentes, $58 \%$ de Engenharia Civil, e 17 respondentes, 90\% de Jornalismo avaliaram que o preenchimento do plano de carreira proporcionou autoconhecimento condição essencial na literatura pesquisada para a efetivação para o planejamento de carreira. Sentiram-se perdidos 3 discentes, $6 \%$ de Engenharia Civil, e o mesmo número de pessoas manifestaram sentimentos "É só um formulário", sugestivo de certo distanciamento da atividade.

\section{Considerações Finais}

O objetivo da pesquisa foi entender planejamento de carreira na perspectiva discente por meio da seguinte questão: Qual o entendimento de planejamento de carreira na visão discente? Para tal, foram analisados 72 planos de carreira, 53 elaborados pelos alunos de Engenharia Civil, e 19 do curso de Jornalismo.

O entendimento de planejamento de carreira foi estabelecido em dois âmbitos da aplicação da metodologia Plano de carreira de Oliveira (2009), e conceito de carreira de Dutra (2002). Plano de carreira envolve a visão de futuro profissional explicitado como um conjunto planejado de estágios interligados às necessidades individuais, empresariais e comunidade; e carreira envolve mudanças de aspirações, padrões de satisfação, autoconcepções e outras atitudes da pessoa voltadas para seu trabalho e a sua vida, considerando as mudanças da sociedade do mundo do trabalho. Este entendimento foi apresentado por 5 discentes, Engenharia Civil, $10 \%$; e 7 do Jornalismo, 37\%.

O estudo permitiu verificar que a gestão pessoal de carreira considerando aspectos de autoconhecimento, com base no desenvolvimento de um referencial próprio nas escolhas profissionais apontados como relevantes na literatura pesquisada, se encontra incipiente no grupo pesquisado. A elaboração do plano de carreira possibilitou autoconhecimento para 31 respondentes, 58,5\% do curso de engenharia civil e de 17 discentes, 89,5\% do curso de jornalismo.

Considerou-se relevante a continuidade do estudo focando na diversidade dos cursos oferecidos nos Campis da referida IES aprofundando os achados de pesquisa e aprofundar os achados de pesquisa, a fim de se estabelecer desafios e perspectivas na elaboração de um plano estruturado de carreira. 
Research, Society and Development, v. 10, n. 3, e20110313199, 2021

(CC BY 4.0) | ISSN 2525-3409 | DOI: http://dx.doi.org/10.33448/rsd-v10i3.13199

\section{Agradecimentos}

Gratidão a todos os discentes cuja participação possibilitou este trabalho. Agradecemos à Universidade do Estado de Minas Gerais Unidade Divinópolis a validação do projeto de pesquisa com participação voluntária de docentes e discentes por meio do Programa Interno de Incentivo à Pesquisa e à Extensão - PROINPE Edital 1/2019.

\section{Referências}

Arthur, M. B., Hall, D. T., \& Lawrence, B. S. (Eds.). (1989). Handbook of career theory. Cambridge University Press.

Bardin, L. (2011). Análise de conteúdo. Edições 70.

Chanlat, J-L. (1995). Quais carreiras e para qual sociedade? Revista de Administração de Empresas Colaboração Internacional, São Paulo, 35 (6), 67-75.

Dutra, J. S. (2002). Gestão de carreira. In: Fleury, M. T. L. (Org.). As pessoas na organização. Gente.

Dutra, J. S. (2009). Gestão de pessoas - modelo, processos, tendências e perspectivas. Atlas.

Dutra, J. S. (2010). Gestão de carreiras na empresa contemporânea. Atlas.

Gil, A.C. (2008). Métodos e técnicas de pesquisa social. Atlas.

Hall, D. T. (2002). Careers in and out of organizations. Sage.

London, M., \& Stumph, S. (1982). Managing careers. Addison-Wesley

Martins, H. T. (2001). Gestão de carreiras na era do conhecimento. Qualitymark.

Minayo, M. C., Deslandes, S. F, Neto, O. C., \& Gomes, R. (2002). Pesquisa social: teoria, método e criatividade. Vozes.

Oliveira, D. P. R. (2009). Plano de carreira: foco no indivíduo. Atlas.

Richardson, J. R. (2017). Pesquisa social: métodos e técnicas. Atlas.

Veloso, E. F. R. (2012). Carreiras sem fronteiras e transição profissional no Brasil: desafios e oportunidades para pessoas e organizações. Atlas.

Yin, R. K. (2005). Estudo de caso: planejamento e métodos. (3a ed.), Bookman. 